\title{
ISOLATION AND CHARACTERIZATION OF EUPLASMIC WHEAT-BARLEY CHROMOSOME ADDITION LINES
}

\author{
A. K. M. R. ISLAM, K. W. SHEPHERD and D. H. B. SPARROW \\ Department of Agronomy, Waite Agricultural Research Institute, The University of \\ Adelaide, Glen Osmond, South Australia, 5064
}

Received 4.viii.80

\section{SUMMARY}

Hybridization of Chinese Spring wheat and Betzes barley using wheat as the female parent gave only 1.3 per cent seed set compared to 15.4 per cent obtained with the reciprocal cross made earlier. Furthermore, only one of the $20 \mathrm{~F}_{1}$ hybrids obtained possessed the normal complement of 28 chromosomes. The others had unusual chromosome numbers ranging from 21-36 in different plants. The 28-chromosome normal hybrid was backcrossed to wheat to produce a heptaploid in the first backcross generation $\left(\mathrm{BC}_{1}\right)$ and subsequently monosomic $(21 \mathrm{II}+1 \mathrm{I})$ and double monosomic $(21 \mathrm{II}+1 \mathrm{I}+1 \mathrm{I})$ additions of barley chromosomes to wheat were isolated in the $\mathrm{BC}_{2}$ generation. The monosomic additions could be divided into five different phenotypic groups and disomic additions were isolated from among their progeny with a very low frequency $(0.63$ per cent $)$. However, some monotelo-disomic additions $(21 \mathrm{II}+1 t \mathrm{II})$ obtained from the progeny of selfed monosomics yielded both disomic and ditelosomic additions in their progeny with a much higher frequency. A sixth addition line was obtained independently from three unusual $F_{1}$ hybrids exhibiting $22 \mathrm{I}, 21 \mathrm{I}+1 \mathrm{II}$ and $25 \mathrm{I}+1 \mathrm{III}$ at meiosis.

Altogether six of the seven possible disomic additions and seven of the 14 ditelosomic additions of barley chromosomes to wheat have been produced. The chromosome 5 addition could not be obtained in a disomic form because the plants carrying this chromosome are self-sterile. The addition lines were initially characterized by their morphological differences from the wheat parent, and subsequently from isozyme studies and heterochromatic banding (N-banding) of chromosomes. Most of these lines showed more asynapsis at meiosis than the wheat parent and all, except addition line 4 , were less fertile than the wheat parent.

\section{INTRODUCTION}

BEGINNING with William Farrer (1904), Australia's pioneer wheat breeder, many attempts have been made to hybridize wheat and barley (Waterhouse, 1930; Gordon and Raw, 1932; Ahokas, 1970) with the aim of producing a new type of crop plant combining desirable features from these two cereals. However, there are no well-substantiated records of any success until the recent work of Kruse (1973) who was able to produce a few hybrid seeds when pollen from diploid, tetraploid and hexaploid wheat was transferred to emasculated spikes of barley. These hybrids were self-sterile and Kruse obtained only one backcross seed after backcrossing the barley $\times$ hexaploid wheat hybrid with wheat pollen. Following this pioneering work of Kruse, attempts were made in our laboratory to hybridize wheat and barley using wheat as the female parent instead of barley. After an initial failure to obtain any seed from a limited number of crosses, barley was then used as the female parent and $F_{1}$ hybrids were obtained without difficulty, especially with the combination Betzes barley $\times$ Chinese Spring wheat (Islam et al., 1975). 
The primary aim of our work was to produce an amphiploid from the hybrid which could be used in further crosses to produce wheat-barley addition lines, following O'Mara's (1940) method for adding individual rye chromosomes to wheat. It was anticipated that these addition lines would be useful for determining the gene content of barley chromosomes, determining the evolutionary relationship between wheat and barley chromosomes, and possibly for transferring desirable characters from barley to wheat. However, all attempts at producing an amphiploid from barley $\times$ wheat $F_{1}$ hybrids failed, but some 49-chromosome progeny (heptaploids) were obtained after backcrossing them with wheat pollen. The heptaploids were again backcrossed with wheat pollen and a few 43-chromosome monosomic addition lines were isolated from among their progeny. However, these plants exhibited partial or complete pistillody and were all self-sterile.

Pistillody was observed to occur sporadically in the $F_{1}$ hybrids, but it became progressively more pronounced as the proportion of barley to wheat chromosomes was reduced in successive backcrosses to wheat. Clearly this pistillody was due to an incompatibility between the nucleus of hexaploid wheat and barley cytoplasm and thus our attempts to produce alloplasmic wheat-barley addition lines proved to be unprofitable.

To overcome this widespread occurrence of pistillody we attempted again to make the reciprocal cross so that the $F_{1}$ hybrids and derivatives would have the cytoplasm of wheat instead of barley. The present paper describes the production of these wheat $\times$ barley hybrids and our progress towards the isolation and characterization of euplasmic disomic addition lines from their progeny. A brief summary of some of this work was presented at the Fifth International Wheat Genetics Symposium in New Delhi in 1978 (Islam, et al., 1978).

\section{MATERIALS AND METHODS}

The main hexaploid wheat parent used was Chinese Spring but two other cultivars, Gabo and Tobari-66 were used to a limited extent. Tobari-66 was obtained from the CIMMYT (Centro Internacional de Mejoramiento de Maíz y Trigo) organization in Mexico and the other two parents were from stocks held at the Waite Agricultural Research Institute. The barley parents included two local cultivars, Ketch and Clipper, and one of European origin, Betzes.

In making crosses, the wheat spikes were emasculated 1-2 days before anthesis and immediately covered with glassine bags to prevent uncontrolled pollination. Two days after emasculation the spikes were pollinated with barley. One day after pollination a droplet of $25 \mathrm{ppm}$ gibberellic acid was applied to each floret and this was repeated each day for 6-8 days, and after a further 6-8 days the embryos were dissected out and transferred to an artificial culture medium. The culture medium was prepared using the basic ingredients of the medium used by Morrison et al. (1959) with added trace elements according to the formulation of Norstog (1973) and $0.2 \mathrm{gm} / 1$ of glutamic acid. The $p \mathrm{H}$ of the medium was adjusted to $5 \cdot 0$. The embryos were placed on 14-18 day old wheat or barley endosperm tissues which earlier had been dissected out aseptically and planted on the agar medium in culture bottles. The $\mathrm{BC}_{1}$ and $\mathrm{BC}_{2}$ seeds did not require embryo culture and matured on the plants. 
The chromosome constitution of the $F_{1}$ hybrids and derivative plants was determined both from root tip cells and pollen mother cells (pmcs). For mitotic studies the root tips were pre-treated for four to five hours in water saturated with $\alpha$-bromonaphthalene and then fixed in glacial acetic acid overnight. For meiotic studies individual anthers with pmcs at metaphase I were fixed in a 3:1 mixture of ethanol and glacial acetic acid. A standard Feulgen staining and squash procedure was used with both root tips and pmcs to prepare material for cytological examination.

Most of the $F_{1}$ hybrids were treated with 0.1 per cent colchicine for approximately 72 hours using Bell's (1950) tiller capping method, in an attempt to induce chromosome doubling. The growth habit, plant morphology and spike characters of the addition lines were recorded on several plants of each line planted singly in potting compost in $30 \mathrm{~cm}$ diameter pots, and grown under natural photo-period in a glasshouse in spring. The seed set on 10 spikes from two to three plants of each addition line was measured also, as an index of their fertility.

\section{Results}

\section{(i) $F_{1}$ Hybrids}

It was much more difficult to cross wheat and barley using wheat as the female parent than it was with the reciprocal cross where hybrids were obtained readily (Islam et al., 1975). The best results were with Chinese Spring wheat and Betzes barley but only 1.3 per cent of the crosses were successful (table 1) compared to $15 \cdot 4$ per cent in the reciprocal cross.

TABLE 1

Census data on wheat $\times$ barley hybridization

$\begin{array}{lrrrrr}\begin{array}{c}\text { Cross } \\ \text { combination }\end{array} & \begin{array}{c}\text { No. of } \\ \text { florets } \\ \text { pollinated }\end{array} & \begin{array}{l}\text { Seeds obtained } \\ \text { No. }\end{array} & \begin{array}{c}\text { No. of } \\ \text { embryos } \\ \text { cultured }\end{array} & \begin{array}{c}\text { No. of } \\ \text { plants } \\ \text { obtained }\end{array} \\ \text { CS* } \times \text { Ketch } & 2731 & 7 & (0 \cdot 2) & 3 & 1 \\ \text { CS } \times \text { Betzes } & 3381 & 44 & (1 \cdot 3) & 19 & 19 \\ \text { CS } \times \text { Clipper } & 902 & 3 & (0 \cdot 3) & 0 & 0 \\ \text { Gabo } \times \text { Betzes } & 759 & 0 & (0 \cdot 0) & 0 & 0 \\ \text { Gabo } \times \text { Clipper } & 182 & 1 & (0 \cdot 5) & 0 & 0 \\ \text { Tobari-66 } \times \text { Betzes } & 178 & 0 & (0 \cdot 0) & 0 & 0\end{array}$

${ }^{*} \mathrm{CS}=$ Chinese Spring wheat.

In the present study, Betzes was a better pollen parent than the Australian cultivars Ketch and Clipper and Chinese Spring was a better pistillate parent than the cultivars Gabo and Tobari-66. Although it was very difficult to obtain seeds from these crosses using wheat as females, the success rate in culturing embryos ( 91 per cent) was better than with the reciprocal cross (49 per cent).

Although 20 hybrid plants were obtained in the present programme, their somatic chromosome number and chromosome pairing pattern at meiosis revealed that only one of them was a proper $F_{1}$ hybrid having the expected 28 somatic chromosomes which form 28 I at meiosis (fig. 1a). The 
other 19 hybrids possessed somatic chromosome numbers ranging from 21 to 36 . Three of these were wheat haploids with 21 chromosomes, five possessed a haploid complement of wheat chromosomes plus one (fig. 1b), two (fig. 1c) and four to six different barley chromosomes (Islam and Shepherd, 1980b). The remaining 11 plants had very abnormal chromosome constitutions including duplication and deficiency of some wheat and barley chromosomes. For example, one hybrid plant had 35 somatic chromosomes and formed $15 \mathrm{II}+5 \mathrm{I}$ at meiosis (fig. 1d).

The normal $F_{1}$ hybrid grew vigorously and resembled the wheat parent in morphological characters as was also observed with the reciprocal hybrid (Islam et al., 1975). The spikes on this plant possessed short awns especially in the upper half of the spike (fig. 2a). The 21-chromosome plants (fig. 2e) resembled Chinese Spring closely except for narrow stems and spikes as expected with wheat haploids. The florets on the spikes of the 23chromosome plant were somewhat larger in size than those produced by the haploids (fig. 2d). However, the other $F_{1}$ plants with very abnormal chromosome constitution produced spikes with numerous abnormalities including excessive awn development, supernumerary spikelets and malformed florets (figs. $2 b, c$ ). All of the $F_{1}$ hybrids were seif-sterile. The normal $F_{1}$ hybrid and three of the unusual hybrids have been used in the production of addition lines and only the results obtained with these four hybrids are included in this paper. The cytological behaviour and possible origin of the other unusual hybrids are described in detail elsewhere (Islam and Shepherd, 1980 $b$ ).

The somatic chromosome number of the normal $F_{1}$ hybrid was not determined from root tip cells, but 28 chromosomes were observed at mitosis in young ovarian tissue. The majority of the pmcs possessed 28 chromosomes at metaphase I of meiosis but some mosaic cells with aneuploid and polyploid numbers were also observed (Islam and Shepherd, $1980 \mathrm{~b})$. Among the 28-chromosome pmcs the majority exhibited 28 I (fig. 1a) but others possessed one or more bivalents with a maximum of five occurring rarely. The average pairing of chromosomes in the 28chromosome cells was $26.51 \mathrm{I}+0.72 \mathrm{II}+0.015 \mathrm{III}$ in 128 cells. An attempt was made to produce an amphiploid from this $F_{1}$ hybrid with colchicine treatment. Although doubled sectors with 56 chromosomes were observed at meiosis in some anthers, no seed set was obtained. However, the plant was found to be partly female fertile and seeds were obtained after pollinating it with the wheat parent. Altogether $99 \mathrm{BC}_{1}$ seeds were obtained with an average of $3 \cdot 5$ seeds/spike.

\section{(ii) Progeny obtained from the normal $F_{1}$ hybrid}

\section{(a) First backcross generation}

Altogether $41 \mathrm{BC}_{1}$ plants were grown and their somatic chromosome numbers ranged from 35-76, with 17 (41 per cent) being heptaploids with 49 somatic chromosomes. Presumably these arose from fertilization of unreduced egg cells resulting from meiotic restitution (Islam and Shepherd, $1980 a$ ). Although there was considerable asynapsis at metaphase I, each of these plants had some pmcs which exhibited $21 \mathrm{II}+7$ I, thus confirming their heptaploid status. In addition, these plants exhibited some chromosome 


\section{Plate I}

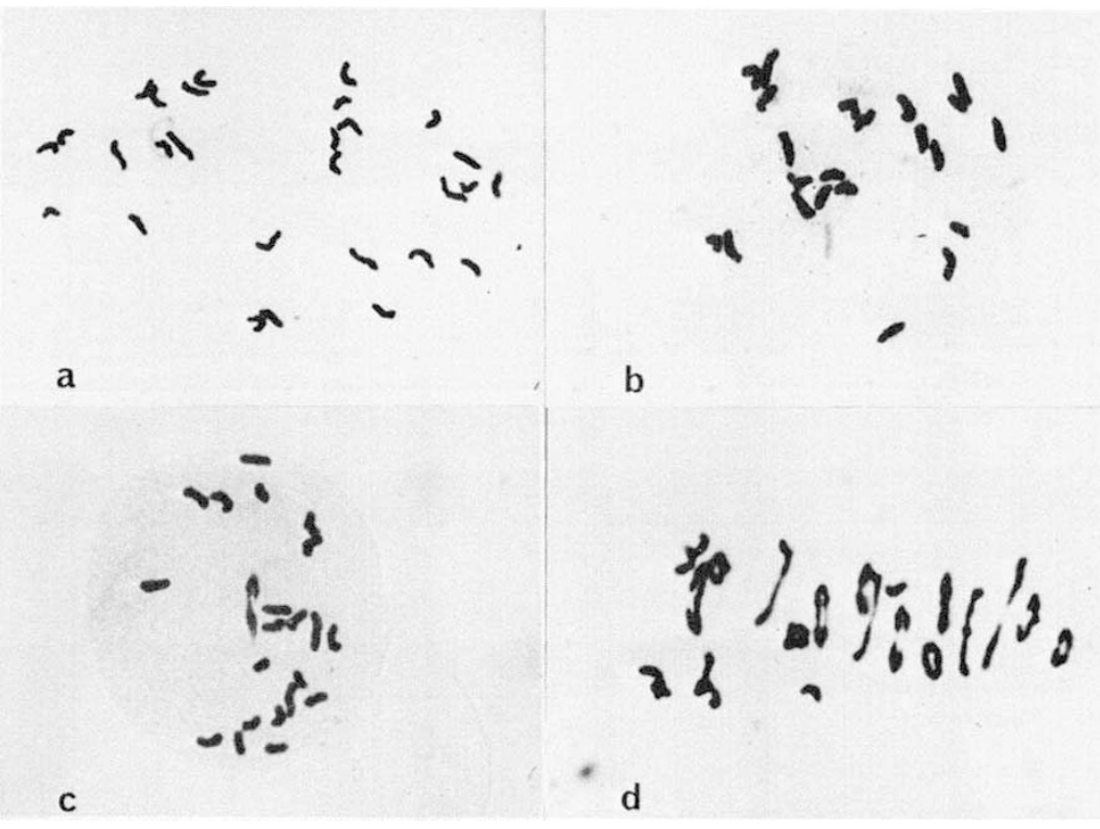

FIG. 1.-Chromosome configurations at metaphase $I$ in pmcs of some wheat $\times$ barley $F_{1}$ hybrids. a, 28-chromosome normal hybrid $(28 \mathrm{I}), \times 700 ;$ b, 22-chromosome hybrid (22 I), $\times 820 ;$ c, 23-chromosome hybrid $(21 \mathrm{I}+1 \mathrm{II}), \times 720$; d, 35-chromosome hybrid $(15 \mathrm{II}+5 \mathrm{I}), \times 970$. 


\section{Plate II}

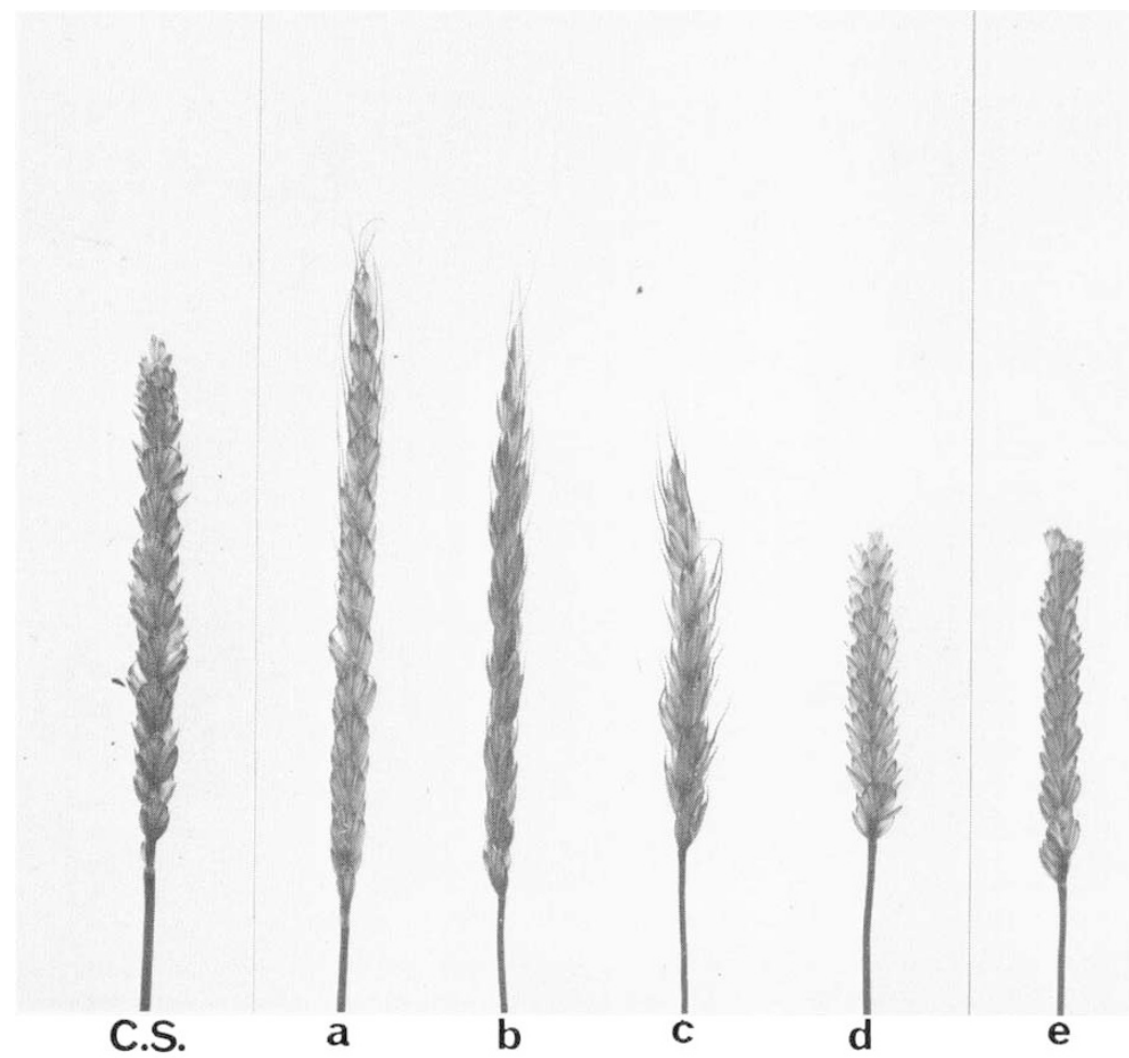

FIG. 2.-Spike morphology of the wheat parent and some wheat $\times$ barley $F_{1}$ hybrids, $\times 0.57$.

C.S., Chinese Spring parent; a, 28-chromosome normal hybrid; b, 31-chromosome hybrid; c, 27-chromosome hybrid; d, 23-chromosome hybrid; e, 21-chromosome "hybrid" (haploid wheat). 
mosaicism in pmcs (Islam and Shepherd, 1980b). The 49-chromosome $\mathrm{BC}_{1}$ plants usually produced fewer tillers than the $F_{1}$ hybrid, but they had broader leaves, thicker culms and more compact spikes with larger florets. However, there was some variation between the heptaploid plants for these characters indicating some influence of environment. In contrast to the fertile heptaploid obtained from wheat $\times$ rye crosses (Riley and Chapman, 1958 ) and wheat $\times$ Agropyron crosses (Dvorák and Knott, 1974) the wheat $\times$ barley heptaploids were self-sterile like the heptaploids from the reciprocal cross. However, $\mathrm{BC}_{2}$ seeds were easily obtained after pollinating them with wheat.

\section{(b) Second backcross generation}

The somatic chromosome constitution of $240 \mathrm{BC}_{2}$ plants was determined from root tip analyses in a search for 43-chromosome putative monosomic addition lines. A wide array of chromosome numbers (35-70) was observed as was also found with the reciprocal cross. Altogether 35 plants with 43 somatic chromosomes were detected and 25 of these were monosomic additions which exhibited either $21 \mathrm{II}+1 \mathrm{I}$ ( 20 plants $)$ or $1 \mathrm{IV}+$ 19 II +1 I (5 plants) at meiosis. The other 10 plants showed more complicated pairing patterns, including two which exhibited very abnormal meiosis with extreme chromosome mosaicism in pmcs (Islam and Shepherd, 1980b). The monosomic addition lines were all self-fertile but some of the other $\mathrm{BC}_{2}$ plants were self-sterile.

The 25 monosomic addition plants could be classified into five different groups based on their morphological differences from normal Chinese Spring wheat and from each other. It was assumed that these groups represented the additions of five different barley chromosomes to wheat and consequently the search for disomic additions was restricted initially to progeny from 1 or 2 plants from each of these groups. A few double monosomic additions $(21 \mathrm{II}+1 \mathrm{I}+1 \mathrm{I})$ selected among the $\mathrm{BC}_{2}$ progeny were also included in the search for disomic additions.

\section{(c) Isolation of disomic and ditelosomic addition lines}

The above material has been used in several different ways to produce the required disomic addition lines. First, root tips from 789 progeny of selfed monosomic additions were screened cytologically to detect rare 44-chromosome plants. Although 317 (40 per cent) of the progeny apparently possessed a complete barley chromosome, or part of one, only five disomic addition lines forming 22 II at meiosis, were detected. However, 25 of the 789 progeny had $43+t$ chromosomes in their root tips and out of 11 plants examined at meiosis, 8 of them had 21 II $+1 t$ II. These plants are monotelo-disomic additions and they proved to be very valuable in our work since, besides being an alternative source of disomic addition lines, they have also yielded ditelosomic addition lines. Six of the 14 possible different additions of barley ditelocentrics to wheat were isolated from among the progeny of such plants. The double monosomic additions $(21 \mathrm{II}+1 \mathrm{I}+1 \mathrm{I})$ gave a higher yield of disomic addition lines ( 2 plants among 101 examined) than the simpie monosomic additions, but the difference is not significant $(P=0 \cdot 2-0 \cdot 1)$. 


\section{(iii) Progeny obtained from other $F_{1}$ hybrids}

Three unusual hybrids with 22, 23 and 28 chromosomes were also used to produce disomic addition lines (Islam and Shepherd, 1980b). One line was produced directly from colchicine treatment of the 22 -chromosome $F_{1}$ hybrid which exhibited $22 \mathrm{I}$ at meiosis. This hybrid possessed a haploid complement of wheat chromosomes plus a single barley chromosome and thus the seeds obtained from doubled sectors produced 44-chromosome progeny which showed 22 II at meiosis. Similarly another disomic addition was obtained directly following pollination of the 23-chromosome $F_{1}$ hybrid, exhibiting $21 \mathrm{I}+1 \mathrm{II}$ at meiosis, with the wheat parent. The majority of the backcross plants possessed 44 chromosomes and showed 22 II at meiosis. Thus the $F_{1}$ hybrid must have had a haploid complement of wheat chromosomes plus a homologous pair of barley chromosomes and must have formed restituted egg cells with 23 chromosomes which gave 44chromosome disomic addition lines directly, when pollinated with wheat. Subsequently the barley chromosome in one of these lines was found to be markedly heterobrachial, unlike any of the chromosomes in Betzes. It was suspected that this chromosome may possess a pericentric inversion with break points near the end of one arm and near the centromere of the other arm to account for its pronounced asymmetry. This suspicion was confirmed later when it was found that the $N$-banding pattern of this chromosome matched that of chromosome 4 of barley except for a long inverted segment involving the centromere (Islam, unpublished).

Disomic addition lines were also obtained from the 28-chromosome hybrid which exhibited 25 I +1 III at meiosis. Each of two seeds produced on this plant after pollination with wheat, gave 47-chromosome $\mathrm{BC}_{1}$ plants which exhibited $21 \mathrm{II}+5 \mathrm{I}$ at meiosis and were self-fertile. A supposed disomic addition line with 44 somatic chromosomes and 22 II at meiosis was recovered directly from cytological screening of the progeny of one of these plants. Two other progeny from the same $\mathrm{BC}_{1}$ plant with $22 \mathrm{II}+t \mathrm{I}$ and $22 \mathrm{II}+2$ I at meiosis also produced supposed disomic additions (22 II) in the next generation of selfing. Two of these three plants with 22 II were alike in morphology, but the third showed increased awn development. Subsequent tests with these plants, described below, showed that the first two plants were in fact the same addition line whereas the other plant was not an addition line but had 20 II of wheat and 2 II of barley chromosomes.

Isozyme studies showed that the first two plants had barley alcohol dehydrogenase $(\mathrm{ADH})$ whereas the other plant with increased awn development possessed $\mathrm{ADH}$ and glutamic oxaloacetic transaminase (GOT) isozymes of barley, known to be controlled by different chromosomes (Hart et al., 1980). Also $N$-banding showed that chromosome 6B of wheat was absent in the awned plant (Islam, unpublished). Hence this plant was deficient for chromosome $6 \mathrm{~B}$ of wheat and possessed two homologous pairs of barley chromosomes. Thus the original $\mathrm{BC}_{1}$ plant exhibiting $21 \mathrm{II}+5 \mathrm{I}$, instead of having 21 pairs of wheat chromosomes must have had only 20 wheat pairs, one pair of barley chromosomes and one wheat chromosome (6B) as a univalent. In two of the 44-chromosome progeny obtained from this plant, the univalent wheat chromosome was present as a pair and thus these plants were true disomic additions. However, in the third 44 -chromosome plant isolated, the wheat 
univalent apparently had been lost and another pair of barley chromosomes was present, thus giving the plant a constitution of 20 II of wheat and 2 II of barley chromosomes.

Besides the disomic addition, a ditelosomic addition for one arm of this chromosome was recovered from the same $\mathrm{BC}_{1}$ plant. This ditelosomic was obtained from a monotelo-disomic addition ( $21 \mathrm{II}+1 t \mathrm{II})$ which had been detected in the progeny of a selfed monosomic addition, which in turn had been isolated from among the progeny derived from backcrossing the $\mathrm{BC}_{1}$ plant to wheat.

\section{(iv) Characterization of the addition lines}

The first disomic addition line was isolated from the 23-chromosome $F_{1}$ hybrid described above and this line was assigned the letter $\mathrm{A}$. The other three disomic additions recovered subsequently from the $F_{1}$ hybrids exhibiting $22 \mathrm{I}$ and $25 \mathrm{I}+1 \mathrm{III}$ at meiosis, closely resembled addition line $\mathrm{A}$ and it was thought that they probably involved the same barley chromosome. A total of 15 disomic additions were recovered from the 5 other groups of monosomic additions and these lines were given the arbitrary designations $B$ to $\mathrm{F}$ in order of their isolation between groups. Altogether there were 5 separate isolations of disomic additions in group B, 3 in group C, 4 in group $\mathrm{D}, 2$ in group $\mathrm{E}$ and 1 in group $\mathrm{F}$. Before characterizing the addition lines it was necessary to prove their authenticity and their individuality. This was accomplished by crossing an addition line from each of the 6 groups with wheat and also completing a half diallel of intercrosses between the different addition lines. At meiosis, the progenies from these crosses gave $21 \mathrm{II}+1 \mathrm{I}$ and $21 \mathrm{II}+2 \mathrm{I}$, respectively, thus confirming that each of the 6 lines were in fact different.

The morphological features which distinguished the monosomic additions from Chinese Spring were accentuated in the disomic additions, and the plant and spike characters of these lines along with the parents, are shown in figs. 3 and 4 , respectively. The principal distinguishing features (morphological and physiological) of the disomic addition lines when grown under glasshouse conditions are listed in table 2 .

Although the addition lines are all morphologically different from Chinese Spring wheat, they do not exhibit any obvious morphological characters of barley and therefore gross morphology has little or no analytical value for identifying which specific barley chromosomes are present in the wheat background. Biochemical characters were then studied in an attempt to overcome this problem and to characterize further the addition lines. Barley prolamins (hordeins) have been used to identify one barley chromosome (G) (Islam et al., 1975), but when present in wheat this chromosome causes sterility (Islam and Shepherd, 1980b) and thus it has not been possible to produce a disomic addition involving chromosome $G$. Several barley isozymes have also proved useful in identifying the barley chromosomes present in addition lines (Hart et al., 1980; Powling et al., 1981) and a summary of these results is given in table 2.

Although these isozyme studies helped to characterize five different addition lines, they did not reveal which barley chromosomes, in terms of their standard nomenclature, were present in the addition lines. This 
TABLE 2

Disomic wheat-barley addition lines and their morphological, physiological and biochemical characteristics

Addition line

$\overbrace{\begin{array}{c}\text { Barley } \\ \text { Initial } \\ \text { designation } \\ \text { present } \\ \text { (Islam, 1980) }\end{array}}^{\text {Astamesome }}$

A

B

$\mathrm{C}$

$\mathrm{D}$

$\mathrm{E}$

F

G
4

7

6

1

2

3

5
Morphological, physiological differences from Chinese Spring

Thick culms and apically awnleted spikes often having supernumerary spikelets

Thick culms and long lax spikes with larger florets and longer anthers

Tapered spikes, with outwardly-curved beaks on lemmas

Bushy at juvenile stage, many tillered with prolonged flowering habit and poor fertility

Prostrate habit at juvenile stage, slender culms with narrow leaves and narrow, elongated florets with awnlets

Similar to Chinese Spring but the spikes are usually smaller and more dense

Not obtained because of sterility
Biochemical*

characters

of barley

$\mathrm{ADH} ; \mathrm{ACPH}$; B-Am

GOT; AMP

EST-1,-2; EP

G6PD

EST-3, -4

Hordeins; PGI;MDH

* $\mathrm{ADH}=$ Alcohol Dehydrogenase; GOT = Glutamic Oxaloacetic Transaminase AMP $=$ Aminopeptidase; $\mathrm{EP}=$ Endopeptidase $; \mathrm{EST}=$ Esterase; $\mathrm{ACPH}=$ Acid Phosphatase $\mathrm{PGI}=$ Phosphoglucose Isomerase; $\mathrm{MDH}=$ Malate Dehydrogenase; G6PD = Glucose-6-phosphate Dehydrogenase; $\beta$-Am $=\beta$-amylase. From Hart et al. (1980) and Powling et al. (1981).

problem was solved by $\mathrm{N}$-banding the somatic chromosomes of disomic barley, barley trisomics and the addition lines (Islam, 1980). This allowed the arbitrary designations given to these addition lines initially to be replaced, as shown in table 2 , with the standard numbering system used for barley chromosomes (Burnham and Hagberg, 1956; Ramage et al., 1961).

\section{(v) Meiotic chromosome pairing, fertility and stability of the addition lines}

To determine whether the added barley chromosomes have any effect on chromosome pairing behaviour at meiosis, the pairing configurations in the 6 disomic addition lines available were compared to those occurring in Chinese Spring wheat.

The frequency of unpaired chromosomes was much greater with additions $\mathrm{A}$ and $\mathrm{D}$ compared to the other lines (table 3 ). The pmcs with less than 22 II exhibited 21 II +2 I with all addition lines except line A where $18 \cdot 8$ per cent fell into this category and $4 \cdot 3$ per cent exhibited $20 \mathrm{II}+4 \mathrm{I}$. It is not clear from these data whether it is unpaired barley or wheat chromosomes which occur as univalents. However, comparison of the chromosome pairing behaviour of the 6 monosomic addition lines with that of Chinese Spring wheat provided further information on this question. Monosomic additions $A$ and $B$ showed a much higher frequency of univalents than Chinese Spring, allowing for the extra univalent in the monosomics, but the difference was significant only with addition $\mathrm{A}(P=0 \cdot 05-0 \cdot 02)$. The level of chromosome pairing in the other 4 addition lines was similar to that in 
Plate III
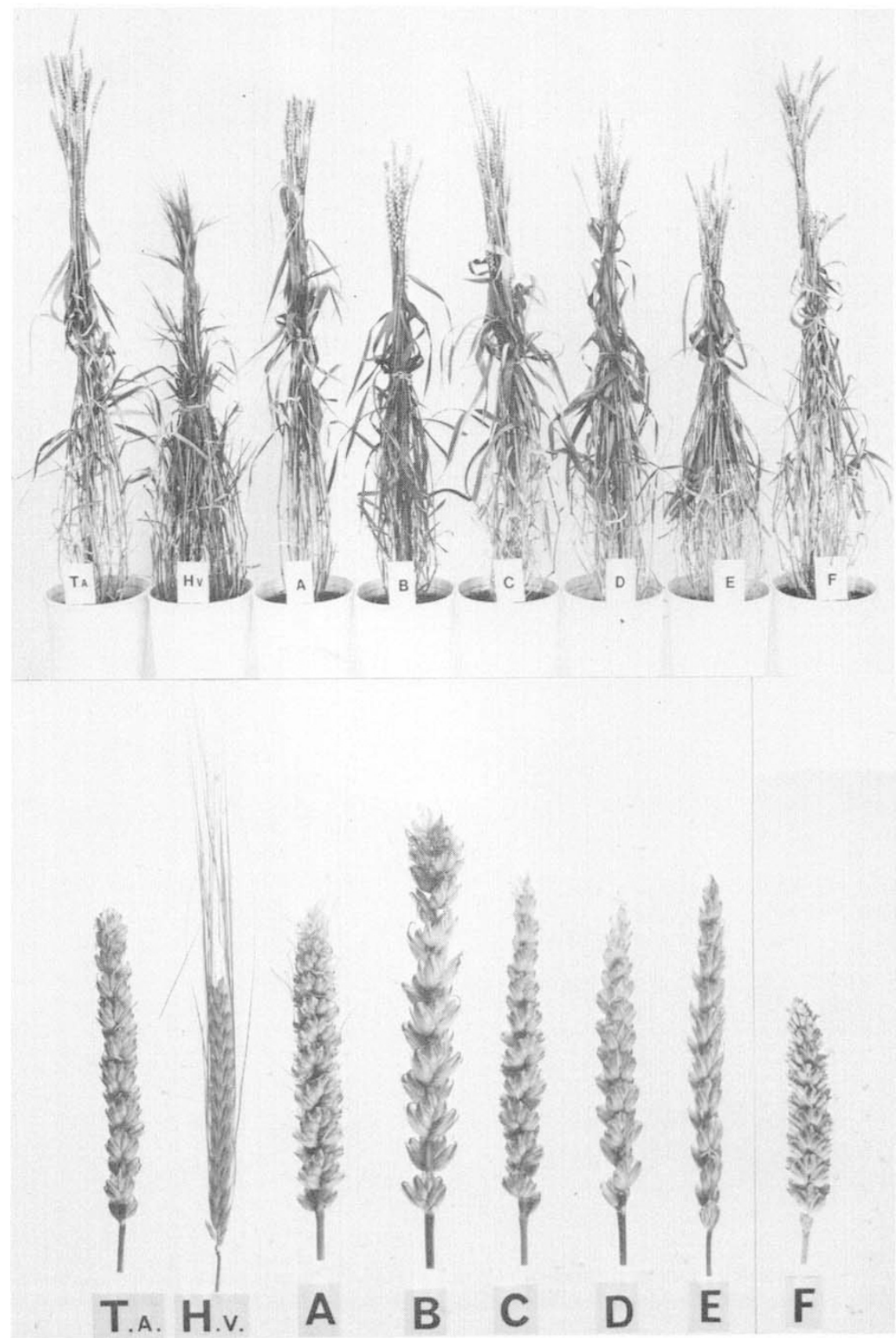

Fig. 3.-Plant morphology of Chinese Spring wheat (T.A.); Betzes barley (H.V.); Disomic additions $\mathrm{A}, \mathrm{B}, \mathrm{C}, \mathrm{D}, \mathrm{E}$ and monotelo-disomic $\mathrm{F}(21 \mathrm{II}+1 t \mathrm{II}), \times 0 \cdot 065$.

FIG. 4.-Spike morphology of Chinese Spring wheat (T.A.); Betzes barley (H.V.); Disomic additions $\mathrm{A}, \mathrm{B}, \mathrm{C}, \mathrm{D}, \mathrm{E}$ and $\mathrm{F}, \times 0 \cdot 55$. 
TABLE 3

Meiotic chromosome pairing, fertility and stability of the disomic addition lines and Chinese Spring wheat

\begin{tabular}{|c|c|c|c|c|c|}
\hline \multirow[b]{2}{*}{ Genotype } & \multicolumn{3}{|c|}{ Chromosome pairing at $\mathrm{MI}$} & \multicolumn{2}{|c|}{$\begin{array}{c}\text { Chromosome No. of } \\
\text { progeny }\end{array}$} \\
\hline & $\begin{array}{l}\text { No. of } \\
\text { pmcs }\end{array}$ & $\begin{array}{c}\% \text { with } \\
\text { bivalents } \\
\text { only }\end{array}$ & Grains/Spikelet* & $\begin{array}{c}\text { No. of } \\
\text { progeny } \\
\text { examined }\end{array}$ & $\begin{array}{c}\% \text { with } 44 \\
\text { chromosomes }\end{array}$ \\
\hline $\begin{array}{c}\text { Parent } \\
\mathrm{CS}^{+}\end{array}$ & 97 & $95 \cdot 9$ & $3 \cdot 70 \pm 0 \cdot 18$ & 一 & - \\
\hline $\begin{array}{l}\text { Disomic } \\
\text { addition }\end{array}$ & & & & & \\
\hline A & 186 & 76.9 & $3 \cdot 62 \pm 0 \cdot 16$ & 50 & $86 \cdot 0$ \\
\hline $\mathrm{B}$ & 69 & $91 \cdot 3$ & $2 \cdot 63 \pm 0.13$ & 30 & $73 \cdot 3$ \\
\hline $\mathrm{C}$ & 51 & $90 \cdot 2$ & $2 \cdot 54 \pm 0 \cdot 11$ & 31 & $93 \cdot 5$ \\
\hline $\mathrm{D}$ & 79 & 84.8 & $1 \cdot 68 \pm 0 \cdot 16$ & 36 & $94 \cdot 6$ \\
\hline $\mathrm{E}$ & 140 & $98 \cdot 6$ & $2 \cdot 62 \pm 0 \cdot 17$ & 35 & $91 \cdot 6$ \\
\hline$F$ & 80 & $90 \cdot 0$ & $2 \cdot 88 \pm 0 \cdot 11$ & 40 & $97 \cdot 5$ \\
\hline
\end{tabular}

Chinese Spring. It can be concluded, therefore, that the presence of barley chromosome A causes significantly increased asynapsis of at least one pair of wheat chromosomes in monosomic additions, and presumably in disomic additions also. On the other hand, it is likely that the increased frequency of univalents observed in disomic addition $\mathrm{D}$ (table 3 ) is due to lack of pairing between the barley chromosomes, unless the presence of two doses of this barley chromosome interferes with the pairing of wheat chromosomes, whereas one dose does not.

There was no evidence of any meiotic pairing between wheat and barley chromosomes in any of the pmcs examined, from the monosomic and disomic addition lines. The fertility of the disomic additions except addition line A was less than that of Chinese Spring (table 3). Although disomic addition line A was the least stable meiotically it was clearly the most fertile of the lines. Addition line D had the lowest fertility and this could be due to the tendency of this line to have non-dehiscent anthers. The stability of these addition lines in terms of their breeding behaviour is set out in table 3 . There was no close correspondence between stability and meiotic behaviour since addition line $B$ was the least stable but showed similar meiotic behaviour to addition lines $\mathrm{C}$ and $\mathrm{F}$. Furthermore, addition line $\mathrm{A}$ exhibited the most irregular meiosis but stability was intermediate between $\mathrm{B}$ and the other additions.

\section{Discussion}

The success rate achieved in the present study with Chinese Spring $\times$ Betzes crosses was much less than that obtained earlier (Islam et al., 1975) with the reciprocal cross. McFadden and Sears $(1944,1946)$ also reported a reciprocal difference in crosses between Aegilops squarrosa L. and Triticum dicoccum Schrank. They failed to obtain any hybrid seed when Ae. squar- 
rosa was used as the female parent but they had no difficulty in making the reciprocal cross. Röbbelen and Smutkupt (1968) observed a similar reciprocal difference in crosses involving Chinese Spring wheat and Petkuser rye. They obtained 61 per cent seed set in wheat $\times$ rye crosses but only 1 per cent seed set in the reciprocal cross. The low seed set obtained in the latter cross was attributed partly to the relatively slow growth of wheat pollen tubes in the style of rye. However, the reason for lower seed set in the wheat $\times$ barley cross is not known. Furthermore, it should be noted that the present work differs from those cited above in that the best cross success was obtained when the lower ploid parent was used as the female.

It is well known that Chinese Spring wheat crosses more readily with rye than do most other wheat cultivars, because it possesses the recessive alleles of the crossability genes $K r_{1}$ and $K r_{2}$ located in chromosomes 5B and 5A, respectively (Riley and Chapman, 1967). Chapman et al. (1976) and Snape et al. (1979) provided evidence that the same gene loci may control crossability of wheat with Hordeum bulbosum L. Although we have no direct evidence on this, it is possible that these genes may also be involved in crossability with barley. An unexpected problem encountered with wheat $x$ barley crosses was the abnormal chromosome constitution of most of the $F_{1}$ hybrids in contrast to the regular 28 -chromosome $F_{1}$ hybrids obtained in the reciprocal cross. The cause of these abnormal hybrids is unknown but it has been postulated that they may arise from spindle abnormalities at the early zygotic division of the hybrid embryos possessing wheat cytoplasm (Islam and Shepherd, 1980 b).

The failure to obtain fertile sectors on the normal 28-chromosome wheat $\times$ barley hybrid cannot be ascribed to the failure of colchicine to achieve chromosome doubling, since doubled sectors were observed at meiosis in at least one of the spikes of the treated plant. The $\mathrm{BC}_{1}$ plants (heptaploids) were self-sterile in contrast to similar heptaploids from wheat $\times$ rye crosses (Riley and Chapman, 1958) and wheat $\times$ Agropyron elongatum (Host) P.B. crosses (Dvorák and Knott, 1974) which are both self-fertile. The $\mathrm{BC}_{2}$ plants on the other hand segregated for self-fertility depending on whether they possessed chromosome 5 of barley (Islam and Shepherd, $1980 \mathrm{~b}$ ). Plants lacking chromosome 5 were always self-fertile including one plant which had $47+t$ chromosomes. Thus it is likely that the self-sterility of the heptaploids and the failure to obtain fertile sectors in colchicine-doubled $F_{1}$ 's is due to the presence of chromosome 5. Furthermore, it was determined that the sterility factor(s) is present on the long arm of barley chromosome 5 since a translccation line was obtained having the short arm of barley chromosome 5 joined to an unidentified arm of a wheat chromosome and this line is self-fertile (Islam and Shepherd, 1980b). However, sterility due to cytoplasmically-induced pistillody which occurred in the barley $\times$ wheat hybrids and their derivatives (Islam et al., 1975) was not observed in any of the plants produced in the present programme since they all possessed wheat cytoplasm.

The low frequency of disomic additions among the progeny of the monosomic additions was not unexpected, since it is well known that such monosomics will produce a high proportion of euploid pollen and this pollen will have a distinct competitive advantage over any 22 -chromosome pollen bearing the alien chromosome in achieving fertilization. The transmission rate of alien chromosomes in 22-chromosome pollen in a wheat background, 
was found to vary with different alien species. Riley and Chapman (1958) and Evans and Jenkins (1960) reported a low transmission rate for the rye chromosomes in selfed monosomic additions of rye to wheat. Sears (1956) estimated the transmission frequency of an Ae. umbellulata Zhuk. chromosome $\left(6 \mathrm{C}^{u}\right)$ in selfed monosomics to be only 1.3 per cent. However, a high transmission rate of 25 per cent for an $A$. intermedium (Host) P.B. telocentric was reported by Knott (1964).

Double monosomic additions seem to be a better source than monosomic additions for the isolation of disomic additions, since besides a tendency for a higher frequency of disomics from the double monosomics they also provide the opportunity to obtain two different addition lines. A higher frequency of disomic progeny from double monosomics is expected on theoretical grounds because 22-chromosome pollen carrying the extra barley chromosome will suffer less of a competitive disadvantage in fertilization in double monosomic additions than in single monosomics, because the proportion of normal 21 -chromosome wheat pollen having a selective advantage is expected to be lower in double monosomics as compared to simple monosomics. Hyde (1953) also used double monosomics to produce five additions of Haynaldia chromosomes to wheat. Cauderon (1966) obtained 13 per cent disomics from among the progeny of a selfed double monosomic addition of Agropyron chromosomes to wheat. However, one particular Agropyron chromosome (TAF 2) was found to be transmitted through the pollen with high frequency. On the other hand, Evans and Jenkins (1960) failed to isolate any disomic additions of rye chromosomes from the double monosomic additions used in their study.

In characterizing the disomic addition lines at least 5 of them can be recognized by their distinctive morphological differences from Chinese Spring with respect to growth habit, culm and leaf width and spike morphology. Similar morphological changes have been noted by Riley and Chapman (1958), Kimber (1967) and Dvorák and Knott (1974) with wheat-rye, wheat-Aegilops and wheat-Agropyron addition lines, respectively. However, most of the phenotypic modifications in wheat-barley addition lines are quantitative in nature as was noted also by Riley and Chapman (1958) with wheat-rye addition lines. There are some similarities between the phenotypic alterations caused by rye chromosomes when added to wheat and the barley chromosome additions described in this study. For example, barley addition 2 resembles rye addition $2 \mathrm{R}$ (=III, Riley and Chapman, 1958; =B, Sears, 1968) and tetrasomics 2A and $2 \mathrm{D}$ of wheat (Sears, 1954) in having narrowing of all organs. This observation raises the possibility that as this rye chromosome is known to be homoeologous with group 2 chromosomes of wheat (Koller and Zeller, 1976), chromosome 2 of barley may also be related to these chromosomes.

Biochemical characters (Hart et al., 1980; Powling et al., 1981) and heterochromatic banding (Islam, 1980) have proved more useful than morphological characters for determining which particular barley chromosome has been added to wheat. In fact, it has been possible to replace the arbitrary letter designations $A$ to $F$ with the standard chromosome numbering system of barley, and it is recommended that future reference to these lines should use these standard numerical designations, at least until their homoeologous relationship with wheat chromosomes is determined. 
The meiotic behaviour, fertility and breeding behaviour of the addition lines are of interest because not only do they indicate the degree to which the barley chromosomes integrate with the genetic system of wheat, but they also influence the ease with which these lines can be maintained. The extent of asynapsis of chromosomes at metaphase I was similar to that occurring in the wheat parent, except with addition line 4 and to a lesser extent in addition line 1. Riley (1960) observed similar variation in meiotic pairing behaviour in different wheat-rye additions. However, Kimber (1967) reported only occasional pairing failure in his wheat-Aegilops disomic addition lines. None of the wheat-barley addition lines were completely stable, but there was no close relationship between stability and meiotic regularity as was also observed by Riley (1960) in wheat-rye addition lines. The stability was, however, within the range reported in wheat-rye (Riley, 1960) and wheat-Agropyron (Cauderon et al., 1973; Dvorák and Knott, 1974) addition lines. The lack of stability in addition line 7 makes it essential to check its chromosome constitution in each generation to maintain the integrity of this line. The estimates of fertility came only from a few plants grown under glasshouse conditions but there was no close correspondence between fertility and degree of meiotic stability. It is likely that genetic factors are more important in determining fertility than the degree of chromosome pairing. Thus if pairing failure occurs with the alien chromosomes, this will tend to increase the frequency of euploid pollen which will result in increased rather than reduced fertility. In general, all of the disomic addition lines have good fertility except for addition line 1, but even in this case it is better than the fertility of rye addition III (Riley, 1960). However, addition line 5 could not be obtained because this barley chromosome causes sterility when added to wheat. Furthermore, this line cannot even be maintained as a monosomic addition because of its extremely low female fertility. It can, however, be maintained as a double monosomic addition when chromosome 6 of barley is also present (Islam and Shepherd, 1980b).

To summarize, it is clear from the different tests applied that six of the seven possible disomic additions and seven of the 14 possible ditelosomic additions of barley chromosomes to wheat, have been produced in this laboratory. These addition lines will be useful in determining the gene corstent of individual barley chromosomes. Already their value for locating genes controlling barley isozymes to particular barley chromosomes has been shown (Hart et al., 1980; Powling et al., 1981). Furthermore, we are interested in substituting barley chromosomes for individual wheat chromosomes to determine whether wheat and barley chromosomes might have retained the same gene synteny (Renwick, 1971) relationship during their separate evolutionary development. Again the chromosomal location of the same isozymes in wheat and barley is expected to help this programme by indicating which wheat and barley chromosome to include in the substitution tests. Finally and more importantly it may be possible to use the wheat-barley addition lines to transfer some desirable agronomic characters of barley to wheat.

Acknowledgement.--The senior author is grateful to the Commonwealth Government of Australia, for the award of a Colombo Plan Fellowship. 


\section{REFERENCES}

AHOKAS, H. 1970. Some artificial intergeneric hybrids in the Triticeae. Ann. Bot. Fenn., 7, $182-192$.

BELL, G. D. H. 1950. Investigations in the Triticinae. I. Colchicine techniques for chromosome doubling in interspecific and intergeneric hybridization. J. Agric. Sci., 40, 9-18.

BURNHAM, C. R., AND HAGBERG, A. 1956. Cytogenetic notes on chromosomal interchanges in barley. Hereditas ( $L$ und), 42, 467-482.

CAUDERON, Y. 1966. Étude cytogénétique de l'évolution du matériel issu de croisement entre Triticum aestivum et Agropyron intermedium. Ann. Amel. Plantes, 16, 43-70.

CAUDERON, Y., SAIGNE, B., AND DAUGE, M. 1973. The resistance to wheat rusts of Agropyron intermedium and its use in wheat improvement. Proc. 4th Int. Wheat Gen. Symp. (Columbia, Mo.), pp. 401-407.

CHAPMAN, V., RILEY, R., AND MILLER, T. E. 1976. The production of wheat haploids by the use of Hordeum bulbosum. Ann. Rep. Plant Breed. Inst. Camb., p. 99.

DVORÁK, J., AND KNOTT, D. R. 1974. Disomic and ditelosomic additions of diploid Agropyron elongatum chromosomes to T. aestivum. Can. J. Genet. Cytol., 16, 399-417.

EVANS, L. E., AND JENKINS, B. C. 1960. Individual Secale cereale chromosome additions to Triticum aestivum. I. The addition of individual "Dakold" fall rye chromosomes to "Kharkov" winter wheat and their subsequent identification. Can. J. Genet. Cytol., 2, 205-215.

FARRER, W. 1904. Some notes on the wheat "Bobs"; its peculiarities, economic value and origin. Agric. Gaz. of N.S.W., 15, 849-854.

Gordon, G. S., AND RAw, A. R. 1932. Wheat-barley matings. Vic. Dept. Agr. J. (Aust.), 30, $138-144$.

HART, G. E., ISLAM, A. K. M. R., AND SHEPHERD, K. W. 1980. Use of isozymes as chromosome markers in the isolation and characterization of wheat-barley chromosome addition lines. Genet. Res. (in press).

HYDE, B. B. 1953. Addition of individual Haynaldia villosa chromosomes to hexaploid wheat. Amer. J. Bot., 40, $174-182$.

ISLAM, A. K. M. R. 1980. Identification of wheat-barley addition lines with $N$-banding of chromosomes. Chromosoma (Berl.), 76, 365-373.

ISLAM, A. K. M. R., AND SHEPHERD, K. W. $1980 a$. Meiotic restitution in wheat-barley hybrids. Chromosoma (Berl.), 79, 363-372.

ISLAM, A. K. M. R., AND SHEPHERD, K. W. $1980 \mathrm{~b}$. Cytological abnormalities in wheat : harley hybrids and their derivatives. Submitted to Can. J. Genet. Cytol.

ISLAM, A. K. M. R., SHEPHERD, K. W., AND SPARROW, D. H. B. 1975. Addition of individual barley chromosomes to wheat. Proc. 3rd Int. Barley Gen. Symp. (Garching, BRD), pp. $260-270$.

ISLAM, A. K. M. R., SHEPHERD, K. W., AND SPARROW, D. H. B. 1978. Production and characterization of wheat-barley addition lines. Proc. 5th Int. Wheat Gent. Symp. (New Delhi), pp. 365-371.

KIMBER, G. 1967. The addition of the chromosomes of Aegilops umbellulata to Triticum aestivum (var. Chinese Spring). Genet. Res., (Camb.), 9, 111-114.

KNOTT, D. R. 1964. The effect on wheat of an Agropyron chromosome carrying rust resistance. Can. J. Genet. Cytol. 6, 500-507.

KOLLER, O. L., AND ZELLER, F. J. 1976. The homoeologous relationships of rye chromosomes 4R and 7R with wheat chromosomes. Genet. Res. (Camb.), 28, 177-188.

KRUSE, A. 1973. Hordeum $\times$ Triticum hybrids. Hereditas, 73, 157-161.

McFADDEN, E. S., AND SEARS, E. R. 1944. The aritficial synthesis of Triticum spelta. Rec. Gen. Soc. Amer. 13, 26-27.

McFADDEN, E.S. AND SEARS, E. R. 1946. The origin of Triticum spelta and its free-threshing hexaploid relatives. $J$. Hered. $37,81-89,107-116$.

MORRISON, J. W., HANNAH, A. E., LOISELLE, R., AND SYMKO, S. 1959. Cytogeneticstudies in the genus Hordeum. II. Interspecific and intergeneric crosses. Can. J. Pl. Sci., 39, 375-383.

NORSTOG, K. 1973. New synthetic medium for the culture of premature barley embryos. In vitro, 8, 307-308.

O'MARA, J. G. 1940. Cytogenetic studies on Triticale. I. A method for determining the effects of individual Secale chromosomes on Triticum. Genetics, 25, 401-408.

POWLING, A., ISLAM, A. K. M. R., AND SHEPHERD, K. W. 1981. Isozymes in wheat-barley hybrid derivative lines. Biochem. Genet. (in press). 
RAMAGE, R. T., BURNHAM, C. R., AND HAGBERG, A. 1961. A summary of translocation studies in barley. Crop Sci., 1, 277-279.

RENWICK, J. H. 1971. The mapping of human chromosomes, Ann. Rev. Genet., 5, 81-120.

RILEY, R. 1960. The meiotic behaviour, fertility and stability of wheat-rye chromosome addition lines. Heredity, 14, 89-100.

RILEY, R., AND CHAPMAN, V. 1958. The production and phenotypes of wheat-rye chromosome addition lines. Heredity 12,301-315.

RILEY, R. AND CHAPMAN, V. 1967. The inheritance in wheat of crossability with rye. Genet. Res. (Camb.)., 9, 259-267.

RÖBBELEN, G., AND SMUTKUPT, s. 1968. Reciprocal intergeneric hybridizations between wheat and rye. Wheat Inform. Serv., 27, 10-13.

SEARS, E. R. 1954. The aneuploids of common wheat. Mo. Agr. Exp. Sta. Res. Bull., 572, $58 \mathrm{pp}$.

SEARS, E. R. 1956. The transfer of leaf-rust resistance from Ae, umbellulata to wheat. Brookhaven Symp. in Biol., 9, 1-22.

SEARS, E. R. 1968. Relationships of chromosomes 2A, 2B and 2D with their rye homoeologue. Proc. 3rd Int. Wheat Gen. Symp. (Canberra, Aust.), pp. 53-61.

SNAPE, J. W., CHAPMAN, V., MOSS, J., BLANCHARD, C. E., AND MILlER, T. E. 1979. The crossabilities of wheat varieties with Hordeum bulbosum. Heredity, 42, 291-298.

WATERHOUSE, W. L. 1930. Australian rust studies. III. Initial results of breeding for rust resistance. Proc. Linn. Soc. of N.S.W. 55, 596-636. 